\title{
UM NOVO PARADIGMA PARA O FENÔMENO DOS \\ REFUGIADOS: Uma revisão do argumento das estruturas \\ binárias do pensamento humano
}

\author{
Artur Andrade da Silva Machado ${ }^{1}$
}

\begin{abstract}
Resumo
O objetivo central deste ensaio é construir um novo paradigma para interpretar o fenômeno dos refugiados. Argumenta-se que o refúgio não é apenas um resultado de condições conjunturais da Ordem internacional, mas uma característica desse arranjo, de modo que sua institucionalização é necessária à concepção de uma sociedade internacional formada por Estados. $\mathrm{Na}$ defesa de tal argumento, um sistema político de governança composto por subunidades estatais é sobreposto às dinâmicas de um mapa social complexo.
\end{abstract}

\section{Palavras-chave}

Refugiados; Teoria; Movimento temporal; Instituto.

\section{Abstract}

This essay aims at providing a new framework for understanding the refugee phenomenon. In this sense, it argues that the refuge constitutes not a characteristic of a momentary development of the international order, but a necessary institute to the conception of a functional effective states' society. To defend such a thesis, a political system of governance organized with cooperative state-unities is attached to a complex social map, thereby making it possible to comprehensively understand the refugee phenomenon.

Keywords

Refugees; Theory; Temporal movement; Institute.

${ }^{1}$ Artur Andrade da Silva Machado é bacharelando em Relações Internacionais na Universidade de Brasília (UnB). 


\section{Introdução}

O objetivo central deste ensaio é argumentar que o refúgio constitui não uma característica de um arranjo político conjuntural da Ordem internacional, mas um instituto necessário à concepção de uma sociedade internacional formada por Estados. Impera mostrar, para cumprir com o proposto, que os refugiados representam uma característica inerente de um sistema político organizado em subunidades estatais e que, por isso, o instituto do refúgio deriva de necessidades de manutenção da legitimidade de tal sistema político.

0 presente argumento beneficia-se enormemente, portanto, das idéias defendidas por Emma Haddad em seu ensaio The Refugee: the Individual between Sovereign (Haddad, 2003), no qual a autora propõe, pela primeira vez, que os refugiados são uma conseqüência inevitável da construção de um sistema de Estados-Nação. Dialogando diretamente com tal texto, este ensaio visa defender que os refugiados são uma parte fundamental do "sistema de Estados-Nação" como hoje o concebemos, mas isso não ocorre, como propõe Haddad, devido à natureza da estrutura binária do pensamento humano e tampouco têm, os refugiados, força constitutiva em relação ao sistema político macroestrutural. Além disso, o presente ensaio ultrapassa a proposta de Haddad na medida em que busca mostrar que o sistema de governança internacional apropria-se do conceito de refugiado de modo a enfrentar um "problema" no nível supranacional e, consequentemente, cria um novo instituto da sociedade de Estados.

Como alternativa aos limites apontados no esquema pioneiro de Haddad, este ensaio busca entender a questão dos refugiados como conseqüência da sobreposição de um plano de organização política macroestrutural a um mapa social complexo, o qual permite transformações constantes nos níveis de atribuição de identidades coletivas. Sob tal perspectiva, argumenta-se ainda que ondas de refugiados (entendidos como indivíduos no interstício de nacionalidades soberanas) ocorrem quando a rigidez do plano político e a maleabilidade do mapa social entram em desarmonia: seja em uma dimensão espacial em que se impõe a rigidez insensível de um sobre as dinâmicas do outro; seja em uma dimensão temporal em que se torna impossível manter o passo sincrônico idealizado em um ponto de origem.

Finalmente, como visa à defesa de um argumento extenso, este ensaio está divido em três fases. Em uma primeira fase, mostro limites no 
fundamento lógico do argumento central de Haddad e aponto para a necessidade de observar a questão dos refugiados sob uma ótica diferente. Na segunda fase, construo um arranjo de organização política macroestrutural que será sobreposto sobre o mapa social na terceira e última fase. Espera-se, portanto, que a partir de tal esquema seja possível argumentar que os refugiados podem ser vistos como uma instituição legítima da sociedade internacional.

\section{A Estrutura Binária do Pensamento e o Ser Parmenidiano}

O objetivo dessa primeira parte do ensaio é apresentar alguns dos limites do fundamento lógico do artigo de Haddad (2003) para que se justifique a construção de um novo arranjo teórico para a compreensão da ligação entre refugiados e o sistema político de Estados nacionais. Para tanto, será necessário apresentar revisões à teoria das estruturas binárias do pensamento humano de Carl Schmitt (1996) que serve de base ao argumento desenhado por Haddad, fato que possibilita transportar as críticas feitas ao primeiro também para o último.

Em The Refugee: the Individual between Sovereign (Haddad, 2003), propondo que os refugiados proporcionam uma identidade-coletiva de "Outro" com poder constitutivo em relação às identidades-coletivas dos nacionais sedentários "normais" e partindo de uma aplicabilidade universal das estruturas binárias de pensamento humano, Emma Haddad advoga que "Refugees are not the consequence of a breakdown in the system of separate nation-states; rather, they are an integral part of the system" (Haddad, 2003, p. 1). 0 argumento de Haddad é de grande importância, nesse sentido, porque é pioneiro em defender que os refugiados são uma parte inerente ao sistema de Estados.

Indo além, Haddad argumenta que os refugiados têm força constitutiva em relação ao próprio sistema de Estados nacionais, na medida em que atuam como sujeitos de referência contrária na construção de identidades nacionais. Para construir tal argumento, a autora se baseia na concepção de realismo político de Carl Schmitt, a partir da qual se entende a política a partir da dicotomia central amigo-inimigo. Em seguida, Haddad executa um procedimento que aqui chamo de sobreposição de dicotomias para mostrar que os refugiados são vistos como Outro, externo, inimigo e base para a construção das identidadesEu das sociedades nacionais. 
Tal seqüência lógica do argumento, no entanto, é falha na medida em que: (i) depende da suposição da universalidade de estruturas binárias do pensamento humano absorvidas da obra de Schmitt (1996); e (ii) segue o problemático raciocínio da sobreposição de dicotomias que forja laços cognitivos contestáveis.

Importante etapa do argumento de Haddad está ancorada na obra de Schmitt. Para esse autor, as diversas esferas do pensamento humano (economia, religião e política, por exemplo) baseiam-se em dicotomias. No caso da política, a dicotomia balizar é a configurada pelas categorias identitárias opostas de amigo e inimigo. Além disso, Schmitt propõe ainda que essas categorias estão mutuamente conectadas na medida em que a existência de uma serve de referência oposta e constitutiva para a existência da outra (Schmitt, 1996).

Essa relação entre os opostos da dicotomia de Schmitt deriva de uma interpretação do que é considerado como a primeira obra filosófica da sociedade ocidental: o poema Da Natureza de Parmênides. Nessa obra, Parmênides traça considerações a respeito da natureza material, oposta às construções humanas. Uma das mais importantes constatações de Parmênides, em relação à natureza, é que o ser é, e o não ser não é. Tal proposição prolonga-se pela teoria positivista da ciência com a tradicional divisão entre ontologia desejável e epistemologia vista como estado de ignorância (Popper; Petersen, 1998).

Uma releitura existencialista, tal como proposta por Schmitt, da proposição de Parmênides acrescenta uma relação de mútua constituição entre os arquétipos de ser e não ser. Cria-se, portanto, uma nova proposição - o ser é porque o não ser não é - segundo a qual um ente não pode existir sem seu equivalente oposto. Tal concepção, aqui nomeada de existencialismo simbiótico, embora já apresente incoerências per se, torna-se ainda mais problemática na medida em que fundamenta uma Teoria de Subjetivação pela Negação ${ }^{2}$ (TSN), segundo a qual as identidades-Eu são construídas de modo a se opor ao referente Outro. Assim, o processo de subjetivação narrado pela TSN atribuída a Schmitt (1996) fundamenta-se na potencialização das diferenças entre duas partes de modo a polarizá-las e a adequá-las ao eixo político amigo-inimigo.

2 Teorias de subjetivação são aquelas que tentam explicar os processos de formações de identidades sociais. 
Partindo de tal marco teórico, Haddad defende que, durante a consolidação das identidades coletivas dos Estados nacionais, havia uma forte preocupação em negar o externo de tal sorte que os nacionais eram definidos a partir de uma negação do não-nacional. Além disso, a autora afirma que tal mecanismo foi responsável por prender indivíduos em uma espécie de limbo inter-fronteiriço de um sistema político moldado por Estados. Tais indivíduos eram os refugiados, vistos, por todas as nacionalidades, como não-nacionais ${ }^{3}$. Uma vez que os refugiados são entendidos como a negação de todas as nacionalidades e do próprio conceito de nacionalidade, peça capital para a organização do sistema de Estados, eles também se tornam ponto de referência cognitiva oposta a esse sistema, o que lhes permite exercer força constitutiva sobre todo o sistema (Haddad, 2003). Contrariando tal argumento, alguns autores advogam que considerar a subjetivação de Estados nacionais de acordo com critérios automáticos - como os da TSN - é desconsiderar os efeitos da variável temporal nesses processos (Bourdieu, 1996; Weber, 1998).

Em alguma medida, é possível argumentar que a TSN fundamenta-se em forte base empírica na medida em que descreve muito bem processos de construção de identidades nacionais de Estados totalitaristas e de Estados no mundo polarizado da Guerra Fria. Segundo a escola realista das Relações Internacionais, em uma concessão implícita à TSN, a unidade do Estado nacional é fortalecida pela ameaça externa (Morgenthau, 2003).

3 A definição de refugiado utilizada neste artigo rebusca o conceito doutrinário, distinto do definido pela Convenção Relativa ao Estatuto dos Refugiados de 1951. Em ocasião da Conferência das Nações Unidas de Plenipotenciários sobre o Estatuto dos Refugiados e Apátridas, o conceito de refugiado se distinguiu do de apátrida. A partir de tal momento, refugiados passam a ser entendidos como indivíduos que cruzam as fronteiras por motivações elencadas em convenção, ao passo que apátrida é aquele desprovido de nacionalidade. Para os efeitos da argumentação do presente artigo, baseado no surgimento dos refugiados como fenômeno histórico, anterior e causador da regulamentação no âmbito do direito internacional, as diferenças entre os conceitos devem ser ignoradas, visto que ambos tratam de um mesmo fenômeno de indivíduos que (contando com um vínculo a uma nacionalidade de origem ou não) não têm direitos à proteção de qualquer Estado nacional dentro do sistema. De fato, anterior à regulamentação ou a qualquer concepção legal, o entendimento de refugiados se mesclava ao de apátrida, já que se reconhecia a impossibilidade de retorno enfrentada pelo primeiro, ao mesmo tempo em que não se contestava a autoridade soberana dos Estados. 
Para as feministas, por outro lado, a construção de identidades segundo concepções binárias de amigo e inimigo deriva de uma leitura masculinizada das relações internacionais e perpetua, portanto, a hierarquia entre os Signos Masculino e Feminino. No entanto, embora vários exemplos possam ser levantados para ilustrar e para contestar o poder empírico do existencialismo simbiótico aplicado à TSN, este artigo defende que tal formulação incorre em falhas essenciais no seu próprio fundamento lógico. Além disso, mesmo o argumento de que a construção das nacionalidades estatais tenha ocorrido de acordo com os preceitos da TSN não é suficiente para garantir que os refugiados constituam parte integrante de um sistema político composto por subunidades estatais. $\mathrm{Na}$ opinião apresentada neste ensaio, o argumento de que os refugiados são uma parte integrante do sistema político de Estados-Nação só pode ser defendido por meio da identificação da interação espaço-temporal de um sistema político rígido com um mapa social em recorrente transformação.

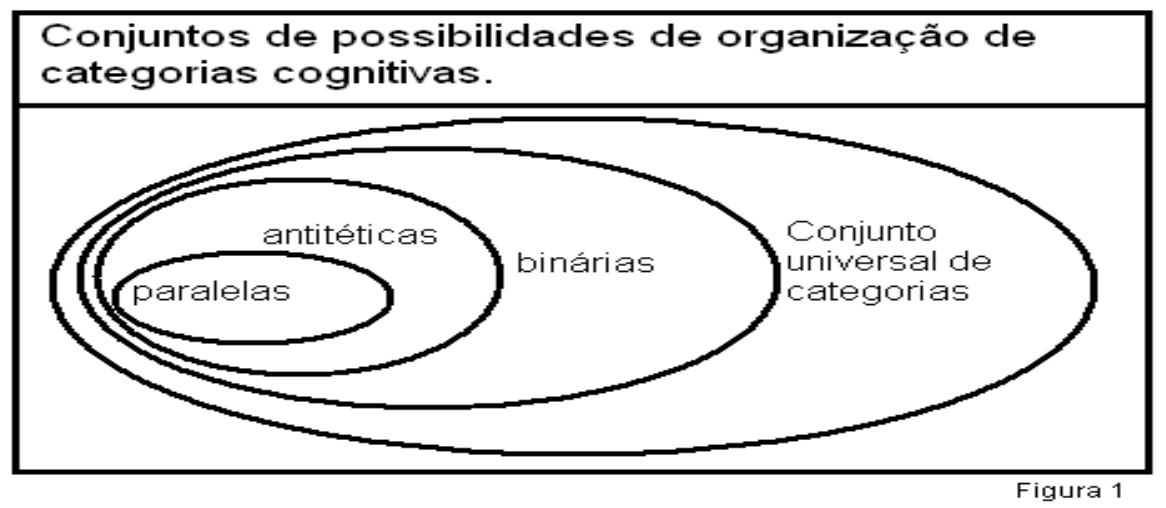

A despeito das diversas críticas que podem ser feitas ao existencialismo simbiótico e à TSN, todas aquelas apresentadas por este ensaio estão resumidas no esquema apresentado na figura 1. Argumento que, embora o existencialismo simbiótico se baseie na crença de que as categorias cognitivas do pensamento humano são sempre formuladas em estruturas binárias, antitéticas e que formam diversos eixos paralelos, tal tipo de arranjo é apenas um entre tantos que permite a capacidade humana de construção cognitiva. De fato, na realidade social, construímos as identidades das outras pessoas e coisas com muitas categorias alternativas àquela do existencialismo simbiótico. Essas diversas possibilidades de organização das categorias cognitivas, como argumentarei a seguir, podem ser entendidas em um sistema de 
conjuntos que guardam relação de pertinência entre si, tal como indica a figura 1 .

Nesse sentido, dentro de um primeiro conjunto universal contendo todas as categorias cognitivas possíveis, é possível destacar um subconjunto menor e não exaustivo: o subconjunto das categorias que se arranjam de maneira binária. Nesse subconjunto, estão todas as categorias que podem se relacionar cognitivamente com apenas e necessariamente uma outra categoria de modo a constituir pares. A formação desses pares advém de alguma espécie de relação exclusiva atribuída socialmente às categorias. Tal relação pode ser de complementaridade, oposição, exclusão antitética, além de outras. No entanto, além dessas categorias, descritas como binárias e reunidas nesse primeiro subconjunto específico, há também aquelas que se organizam em trios, tripés, quadras, que são naturalmente isoladas, etc. Não pretendo levantar séries de exemplos de categorias não-binárias do pensamento, mas certifico que qualquer categoria de pensamento cognitivo que relacione mais ou menos de dois signos sociais pode ser entendida como não-binária. Nesse sentido, os três tipos puros de legitimidade de Weber (racional, tradicional e carismático), bem como categorias sem equivalente oposto ou complementar constituem categorias não-binárias.

A despeito da grande variedade de possibilidades de geografias cognitivas para cumprir com a argumentação deste ensaio, apenas uma menção sobre a existência de categorias que se organizam de maneira não-binária já é suficiente. Tal compreensão, de que o pensamento humano não é sempre binário, nos remete para a primeira falha do pensamento do existencialismo simbiótico: a tendência de transformar todas as estruturas de possibilidades cognitivas em arranjos binários. Essa tendência deve-se uma predisposição de analisar qualquer sistema com a estrutura binária exaustiva do signo e do não-signo. Sob essa perspectiva a qualquer signo passa a corresponder um anti-signo formado pela agregação do advérbio não à identidade original. Tal estrutura é exaustiva na medida em que se assume que tudo o que não é signo passa a ser seu oposto, o não-signo. No entanto, esse tipo de pensamento é limitado, pois restringe uma multiplicidade de signos para um único signo negativo oposto ao ponto original. 


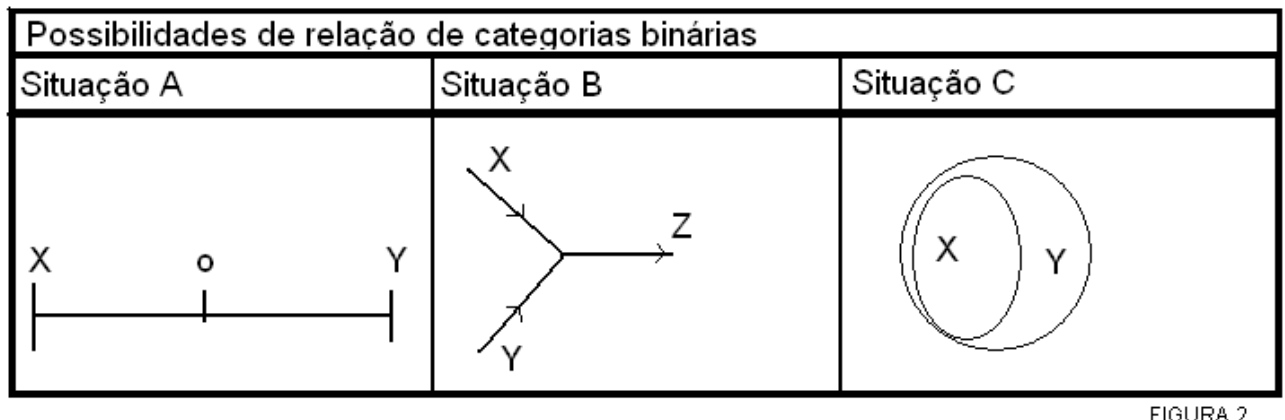

Mesmo dentro do conjunto de categorias binárias, o subconjunto dos pares constituídos por partes em relação de oposição não é exaustivo. Isso porque a relação que se desenha entre dois signos sociais não necessariamente deve ser de exclusão antitética, mas também pode constituir complementaridade ou oposição como indica a figura $2 \mathrm{Na}$ figura 2, há três situações em que os signos $\mathrm{X}$ e $\mathrm{Y}$ constituem categorias binárias, mas com relações distintas. Na situação A, X e Y estão em exclusão antitética, pois, conforme um ponto móvel sobre o eixo se aproxima de $\mathrm{X}$, esse ponto se afasta inevitavelmente de Y. Um exemplo de categorias formadas com relação de exclusão antitética é o do espectro formado pelos opostos de amigo e inimigo, já que conforme determinado indivíduo caminha em direção ao ponto de ser considerado meu amigo, ele se afasta automaticamente do ponto de ser considerado meu inimigo e vice-versa. Na situação $B$, diferentemente, $X$ e Y são vetores de forças opostas, mas de sua interação surge um terceiro vetor $\mathrm{Z}$ que reúne características de $\mathrm{X}$ e Y. Exemplo desse tipo de relação B são os desenhos dialéticos de Marx e Hume, que opõem determinada tese à correspondente anti-tese de modo a construir uma resultante: síntese. Finalmente, na situação C, X e Y são ambos partes de um conjunto maior, de modo que um passa a ser o par complementar e não oposto do outro. Exemplo do tipo de relação que ocorre em C, é aquela entre os signos animais vertebrados e invertebrados, pois o que separa tais signos é uma dicotomia classificatória e não de exclusividade antitética.

Tais constatações nos remetem à outra falha do existencialismo simbiótico que é sua tendência problemática à criação de dicotomias antitéticas. Assim, o existencialismo simbiótico, devido a sua própria crença de que para todo ser há um referente não ser que o constitui, desconsidera que as dicotomias antitéticas são apenas uma categoria especial de relação dicotômica na qual as partes estão diametralmente polarizadas. Enxergando oposição em todos os sistemas, o existencialismo simbiótico confunde, portanto, dicotomia com antítese 
e esquece-se de que dicotomias não passam de uma maneira de classificar um conjunto de duas partes, estando elas em oposição direta ou não. Nesse sentido, certo e errado estão organizados de maneira dicotômica porque representam um conjunto binário de categorias de valor, mas também a divisão clássica dos animais entre vertebrados e invertebrados representa uma dicotomia. Ao contrário do que sugere o pensamento do existencialismo simbiótico, o que permite ao sistema certo-errado constituir uma dicotomia é menos o fato de representarem uma antítese do que suas equivalências de sentido que os unem em um conjunto maior de categorias valorativas.

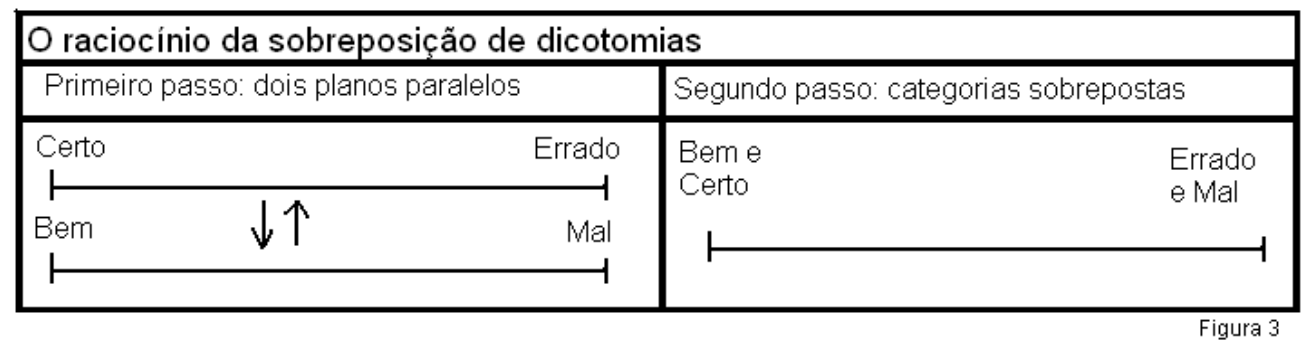

A terceira e última falha que aqui apresento ao pensamento do existencialismo simbiótico questiona uma espécie de raciocínio que aqui chamo de sobreposição de dicotomias indicado na figura 3. Isso porque, ao construir todas as relações sociais em bases binárias diametralmente opostas, essa teoria tem a tendência de conectar os extremos de um eixo aos extremos de outro para construir um único eixo com força explicativa. Esse tipo de raciocínio é uma espécie de esforço cognitivo muito comum na vida social e consiste em dois passos básicos: (i) encontrar dois eixos de continuums paralelos constituídos por categorias opostas; e (ii) imaginar laços de correspondência entre os extremos de cada eixo. Assim, por esse processo, os extremos bem e mal, por exemplo, são ligados cognitivamente (sobrepostos) a certo e errado, doença e saúde, racionalidade e irracionalidade, democracia e autoritarismo, capitalismo e comunismo, Estados Unidos e União Soviética, feminino e masculino. Muitas dessas cognições são largamente aceitas por coletividades e determinadas sociedades, mas nenhuma delas pode ser dita universal porque a cognição social é sempre manipulável no campo discursivo. Assim, mesmo em uma sobreposição de dois eixos paralelos, não há como garantir qual será a posição dos extremos no nível de cognição societário. 


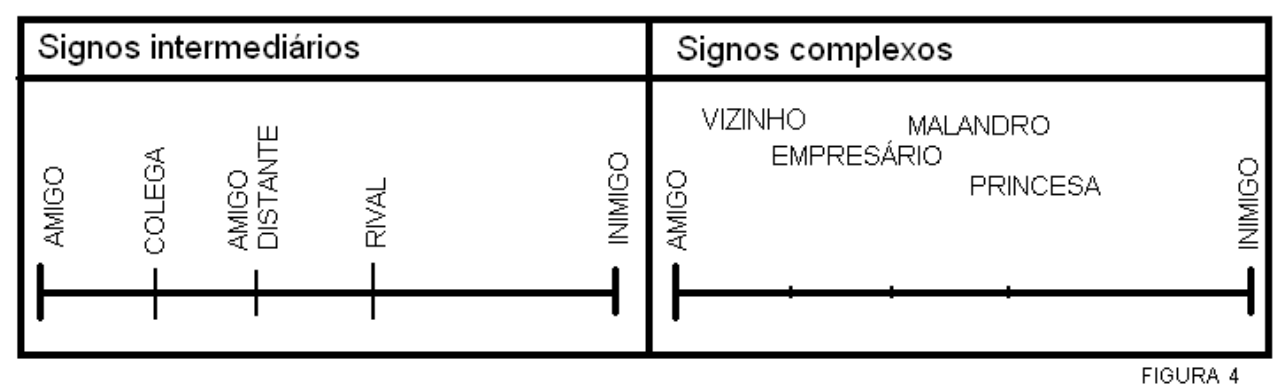

O mecanismo fica ainda mais incoerente quando se passa a sobrepor categorias que não correspondem a eixos binários, antitéticos e paralelos. Para entender melhor essa anomalia no raciocínio de sobreposição de dicotomias é necessário pensar como as categorias binárias se relacionam com signos sociais diversos. A figura 4 indica como a categoria binária amigo-inimigo do existencialismo simbiótico de Schmitt se relaciona com signos sociais diversos. Assim, ao pensamento binário amigo-inimigo acrescentamos diversos outros signos que podem ser de tipo intermediário ou complexo dependendo de como se relacionam com o eixo em questão. 0 que diferencia os signos engajados em cada um desses tipos é que alguns deles podem ser planificados sobre um espectro linear entre opostos binários; reiterando, de tal sorte, o argumento do existencialismo simbiótico; ao passo que outros guardam relações mais complexas com tal espectro. Muitas vezes, os signos que mantêm relação complexa com um composto binário antitético não derivam de categorias binárias paralelas, mas configuram outro tipo de geometria, como eixos transversais, categorias opostas e angulares, tripés, círculos tautológicos etc.

Assim, como indica a figura 4, mesmo partindo de geometrias cognitivas binárias e antitéticas, é possível distinguir entre categorias que guardam relação intermediária e outras que se relacionam apenas de maneira complexa com determinado espectro de opostos. Os signos intermediários (como colega, amigo distante, conhecido ou rival) são assim considerados porque podem ser planificados em um continuum no qual os extremos opostos são, por exemplo, amigo e inimigo sem prejuízo para seu entendimento coletivo ou social. Por outro lado, os signos complexos (tais como vizinho, malandro, preguiçoso, princesa, empresário), quando muito compõem eixos diversos, não paralelos e distanciados angularmente ao eixo amigo-inimigo. Os signos complexos existem de maneira independente ao eixo amigo-inimigo de forma que só podem ser sobrepostos a ele de acordo com critérios estabelecidos por cada indivíduo. Muitas das categorias em questão sequer são 
binárias, como é o caso do vizinho (sem par imediato); outras impõem dificuldades para o estabelecimento de pares antitéticos. Assumindo uma estrutura binária, por exemplo, o oposto do signo princesa pode ser concebido como a plebéia, o príncipe ou a madrasta malvada dependendo de sob qual sistema de lentes se analise a questão.

Em resumo, a maior crítica que é possível fazer ao existencialismo simbiótico é que as antíteses são por vezes construídas arbitrariamente em três passos falhos. Em um primeiro passo, considera-se que as categorias de pensamento e, portanto, o mundo é todo constituído por categorias binárias. Em um segundo passo, assume-se que todas as categorias binárias mantêm uma relação de oposição absoluta e são, dessa forma, antitéticas. E em um terceiro passo, contrastam-se as múltiplas categorias criadas de modo a constituir um sistema rígido e polarizado de valores. No entanto, todas essas etapas apresentam falhas fundamentais já que assumem erroneamente que determinados conjuntos de categorias são exaustivos.

Segue que todas as críticas aqui colocadas podem ser estendidas ao texto de Emma Haddad, porque o existencialismo simbiótico e a TSN fundamentaram seu argumento. Para Haddad, os refugiados são alocados em um extremo de oposição cognitiva em relação aos cidadãos "normais" (que contam com a proteção do Estado). É claro que tal proposição é passível de ser defendida se forem levantadas fontes históricas que comprovem que de fato as identidades dos Estados nacionais foram constituídas em oposição a um signo imaginário de cidadão sem Estado. No entanto, como mostra a argumentação desse artigo, essa proposição não é, de maneira nenhuma, automática ou passível de ser aceita sem problematização, já que as estruturas binárias antitéticas do pensamento humano são apenas uma entre várias outras que compõem nossas alternativas de cognição.

Aceitar essa proposição, tal como formulada por Haddad, é aceitar que a existência dos Huguenotes ${ }^{4}$ era essencial para a formação da identidade da França, o que é muito contestável. 0 fato de a França católica ter classificado os Huguenotes, que eram protestantes, como alien em relação à sua própria formação social não significa que a formação de uma França católica dependeu da existência ou da referência aos Huguenotes. Tampouco é possível dizer que durante a formação

${ }^{4}$ Huguenotes foram uma coletividade de protestantes que, por terem sido expulsos do território francês durante o processo de construção de identidade nacional do país, são por vezes considerados como o primeiro exemplo de fluxos de refugiados da história. 
nacional da Alemanha, ou de qualquer outro Estado-Nação, havia uma preocupação em diferenciar-se de um tipo específico de cidadão sem Estado. Os refugiados, pelas suas características de anomalia, podem representar o oposto à normalidade do sistema de Estados, mas não há nenhuma evidência de que eles tenham sido considerados como oposto referencial para a constituição de identidades nacionais específicas.

Não obstante muitas identidades nacionais tenham sido construídas, como propõe a TSN, pela negação de um outro externo, os refugiados, como parcela quase que insignificante deste, não parecem ter sido fundamentais para a constituição de nenhuma identidade nacional. Tal argumentação, presente no artigo de Haddad (2003) foi, na verdade, fruto de uma sobreposição de dicotomias mal sucedida que tentou ligar a oposição entre a normalidade e a anomalia no plano sistêmico às oposições circunstanciais que deram origem às diversas identidades nacionais.

Além disso, o argumento de Haddad parece ignorar as variáveis de espaço e tempo, pois a autora advoga que a partir do momento em que os refugiados são entendidos como Outro em relação a diversas nacionalidades, eles passam a ser considerados como referente oposto também em relação ao sistema político de Estados. 0 automatismo inerente a tal argumento advém do pensamento do existencialismo simbiótico ao qual é impossível conceber qualquer signo social sem um equivalente oposto imediato. Sob tal perspectiva, o fenômeno dos refugiados ocorreria automaticamente ao longo de toda a extensão (geográfica e temporal) do sistema político de Estados nacionais. A maior incoerência desse tipo de raciocínio evidencia-se, no entanto, na ponderação de que mesmo a concepção de um sistema político organizado por Estados nacionais com identidades excludentes não é suficiente para garantir o surgimento de refugiados independente das marchas geográfica e histórica. Em outras palavras, não é porque existem Estados nacionais com identidades excludentes que automaticamente passam a existir refugiados como referente oposto a tal sistema. Em última instância, aqueles que ficaram excluídos de nacionalidade em determinado momento poderiam se reunir para formar novas unidades estatais em outro momento não fosse a rigidez temporal do sistema político pensado em um determinado ponto de origem.

Tais considerações, embora não invalidem a consideração de que os refugiados representam conseqüência imediata do sistema de Estados, minam a base lógica da argumentação de Haddad, na medida em que 
negam a universalidade da estruturação binária e antitética do pensamento humano. Na próxima sessão deste ensaio, portanto, tentarei construir uma explicação para o surgimento de refugiados a partir da perspectiva de uma teoria de organização macroestrutural onde o problema dos refugiados aparentemente encontra seu locus original.

\section{Um Novo Paradigma ${ }^{5}$ para o Fenômeno dos Refugiados}

A questão dos refugiados precisa ser interpretada por um novo arranjo teórico. Neste ensaio, defendo que a questão é mais bem abordada sob a perspectiva de uma teoria de interação das dinâmicas sociais e políticas no nível macroestrutural. Portanto, o fenômeno dos refugiados deve ser entendido como fruto da interação entre um sistema político de governança formado por Estados nacionais e um mapa social complexo, ao qual tal sistema será sobreposto. A motivação para estudar a questão sobre tal ótica deriva de duas hipóteses: uma primeira que sugere, como a própria Haddad, que os refugiados parecem surgir de anomalias no nível do próprio sistema de Estados; e outra que contesta a suficiência do sistema político para a constituição do fenômeno.

Como consideração inicial ao exercício que se segue, assumo que o sistema político de Estados nacionais apresenta um mal de origem. Devido aos valores que incorpora desde sua fundamentação, ele assume uma pretensão uniformizadora sobre o plano geográfico planetário e têm a tendência de se perpetuar ao longo do eixo histórico. Ambas essas tendências derivam de uma crença da modernidade européia na superioridade de sua própria posição dentro de um paradigma de progresso universal (Shapiro, 2000). Segundo Bourdieu, uma vez concebido o Estado nacional, este passa a reproduzir dinâmicas discursivas que o transformam em uma espécie de entidade históricotranscendental, no sentido de que passa a se proteger das variações temporais (Bourdieu, 1996). Sob essas perspectivas, o sistema político dos Estados nacionais é rígido e insensível à transformação histórica, recorrendo, sempre, ao seu próprio paradigma fundamental para constantemente se reinterpretar e se relegitimar. Por essas razões, para

${ }^{5}$ Paradigma, como utilizado neste ensaio, não faz referência ao entendimento kuhniano do termo. 
Campbell, as entidades que não estão sincronizadas à temporalidade do Estado passam a ser associadas como elementos oposicionistas e externos (Campbell, 1996).

Com o intuito de mitigar o caráter anistórico da tradicional interpretação do fenômeno dos refugiados, dedicarei toda a seção final do ensaio para simular o desenvolvimento da interação entre os planos político e social definidos. No entanto, para reproduzir os processos ideacionais e ideológicos que fundamentam os delineamentos da concepção do sistema político estatal, descreverei tal interação primeiro no campo teórico, que será oportunamente complementado com equivalentes históricos. Essa medida visa mostrar que, mesmo em uma situação original em que a interação entre o sistema político e o mapa social seja perfeitamente harmônica, quando entra em jogo a variável tempo os refugiados surgem como característica inerente à tal interação.

Para seguir com tal proposta, desenvolverei um raciocínio de duas etapas (que herda enorme contribuição do mecanismo do véu de ignorância rawlsiano). Dessa maneira, em uma primeira etapa, permitem-se ajustes migratórios realizados sob um véu de ignorância antes de submeter o modelo a seus próprios desenvolvimentos históricos. Com tal mecanismo, espero mitigar as conseqüências de uma primeira sobreposição do político ao social que ocorre apenas no campo teórico. Assim, em uma primeira etapa puramente teórica, depois de se formular as diretrizes do modelo de governança política, este será sobreposto ao mapa social, mas permitir-se-á livre movimento das massas sociais de modo que se reorganizem pela discrição de convergência de interesses no nível de identidades coletivas.

Nesta seção do ensaio, portanto, apresentarei o sistema político que será sobreposto ao mapa social na próxima seção. A característica mais fundamental de um sistema político de Estados nacionais é que ele é constituído por unidades existentes em um nível intermediário entre o planetário e o individual. Essas unidades são similares, no sentido de que compartilham determinados critérios constitutivos (como fronteiras, jurisdição exclusiva e soberania externa), mas contam com recursos (de poder e de riqueza) desigualmente distribuídos. 
Outro ponto inicial para a formulação do sistema político é definir o tipo de tal sistema. Segundo Kant, tal como interpretado por Wight, arranjos de governança no nível supranacional só podem existir em duas configurações específicas: um modelo de império universal despótico; ou em uma sociedade de unidades autogovernáveis e dispersas que acordem em normas básicas para reger sua convivência no plano internacional (Wight, 1991). A última formação será, de agora em diante, chamada de Sociedade Internacional.

Assim, como este ensaio aceita a tese de que o meio internacional foi, ao longo de sua história, predominantemente anárquico, no sentido de que nunca houve um império universal capaz de impor sua jurisdição a todas as outras entidades políticas que compunham o sistema no qual aquele se engajava (Buzan, 1993; Bull, 2001; Waltz, 1991; Watson, 2004), assume-se também que a configuração política de um regime de governança supranacional deve configurar uma Sociedade Internacional como acima proposto. Assume-se ainda que os recursos e o poder das unidades de tal sociedade (os Estados) são distribuídos desigualmente.

Nessas condições, a primeira característica dessa teoria deve ser a existência de mecanismos de governança supranacionais legítimos, o que já é fato controverso per se. Deve-se aceitar esse pressuposto, no entanto, devido à necessidade de incorporação de normas para refugiados em nível supranacional, já que somente a partir do reconhecimento de tal necessidade seria possível conceber o refúgio como instituto inerente à sociedade de Estados.

O principal objetivo desta seção do ensaio é definir as bases do sistema político para o qual seja possível conceber a institucionalização do refúgio como necessária e legítima para tal organização. A legitimidade dos mecanismos de governança aqui desenhados é ponto fundamental da teoria do ensaio, pois é a partir dela que se argumenta sobre a tendência em institucionalizar o refúgio. Para não restringir a validade do argumento apenas ao campo normativo, busco definir legitimidade em dois níveis aceitos pela coletividade dos Estados: o da legitimidade funcional (advogado por autores realistas); e o da legitimidade normativa (advogado por autores idealistas). 
A teoria, além disso, deve ser aplicável à realidade, o que tentarei garantir não por sua equivalência a evidências empíricas, mas dialogando com outras formulações similares já aceitas pela comunidade científica. Nesse sentido, para contornar uma atual questão de dissenso entre os principais teóricos da sociedade internacional, o modelo formulado neste ensaio evitará se posicionar em relação ao debate entre Pluralistas e Solidaristas ${ }^{6}$, argumentando que o instituto do refúgio é absorvido pela normativa do sistema político desenhado para satisfazer necessidades tanto de Ordem, como de Justiça.

Tudo o que temos até agora é, portanto, um esqueleto de organização macroestrutural baseado na coordenação de unidades (similares, mas contando com recursos desigualmente distribuídos) existentes em um nível intermediário entre o planetário e o individual. Para que essas unidades possam se coordenar, no entanto, é necessário que elas aceitem a existência de normas válidas para a sua coletividade. No presente modelo, entretanto, a seleção de tais normas ocorrerá por reivindicações de legitimidade organizadas também em formato de suposição teórica. Reitero que a legitimidade é importante porque se tenta construir um modelo de organização macroestrutural com um mínimo grau de efetividade, ou seja, que cumpra sua função de organizar a sociedade planetária. Nesse sentido, há duas maneiras de as deliberações imaginadas dentro desse mecanismo serem aplicáveis: (i) por imposição seletiva da vontade das unidades com maior capacidade material em relação às outras; ou (ii) por reconhecimento da legitimidade (por parte das unidades) da deliberação gerida no nível supranacional.

Para que as deliberações criadas no nível supra-unitário sejam efetivas, impera, no entanto, que sejam vistas como legítimas. Mesmo entre os teóricos realistas a legitimidade é importante porque, em algum grau, a teoria política aceita que há exigência de legitimidade mesmo em situações de imposição de normas pela força. Ainda, as deliberações apresentadas pelo sistema de tomada de decisão devem ser

${ }^{6} 0$ debate entre pluralistas e solidaristas, típico da epistemologia da escola inglesa, envolve dois segmentos que divergem no caráter ontológico da sociedade internacional vigente. Para aprofundamento neste ponto, ver Buzan (1993). 
normativamente justificáveis porque se pretende construir, com este modelo, um sistema de atribuição de legitimidade mais holista em comparação com o dos realistas que supõe e depende da existência de racionalidade em cada unidade. Para que as unidades aceitem as deliberações no nível superior como legítimas, impõem-se duas condições: (i) que a estrutura de tomada de decisão seja vista como legítima e (ii) que cada unidade componente dessa estrutura seja percebida como legítima pelas outras. Para cada um desses níveis devese procurar atender a dois tipos de legitimidade: a racional e a moral.

Sob um ponto de vista racional realista, para que a estrutura seja vista como legítima, exige-se que ela seja funcionalmente benéfica. Assim, segundo a Teoria da Estabilidade Hegemônica (Gilpin, 1991), atores egoístas e racionais aceitam as regras impostas por uma unidade mais forte desde que o sistema seja preferível à condição de anarquia total que figurava anteriormente e que o custo para mudança de tal sistema seja racionalmente desinteressante para todas as unidades no sistema. Sob uma perspectiva mais normativa, por outro lado, exige-se, no mínimo, que ela respeite a eqüidade entre as partes (Rawls, 2002).

Como proposto, a legitimidade das unidades deve ser abordada em duas frentes: a externa e a interna. Do ponto de vista externo, é racionalmente vista como legítima a unidade que é capaz de cumprir com seus compromissos com as outras partes e é normativamente vista como legítima a unidade que respeite as normas supranacionalmente acordadas. As respostas das outras unidades em relação a partes vistas como ilegítimas variam do isolamento (rejeição de relacionar-se comercialmente) à intervenção.

Do ponto de vista interno, é racionalmente vista como legítima a unidade que seja capaz de promover a segurança de seus cidadãos, no sentido de que os indivíduos sejam protegidos da anarquia externa e interna - o não cumprimento dessa condição significa a destruição da unidade por forças que partem de seu próprio interior. A legitimidade moral interna de uma unidade, por outro lado, não é passível de ser precisada na medida em que admite infinitas variações, o que se sabe é que o castigo para descumprimento da validade normativa interna é a substituição do regime político daquela unidade. 


\begin{tabular}{|c|c|c|c|}
\hline & Expectativas/Exigênc & sobre as unidades & Exigências sobre o sistema \\
\hline \multirow{2}{*}{$\begin{array}{l}\text { critério } \\
\text { racional }\end{array}$} & Expectativas externas & Exigências internas & \multirow{2}{*}{$\begin{array}{l}\text { Funcionalmente benéfico: deve ser } \\
\text { prefirivel à anarquia e os custos de } \\
\text { reformar o sistema devem ser maiores } \\
\text { que as expectativas de retorno por } \\
\text { fazê-lo }\end{array}$} \\
\hline & $\begin{array}{l}\text { capacidade de cumprir } \\
\text { compromissos com as } \\
\text { outras partes }\end{array}$ & $\begin{array}{l}\text { proteçẫo dos cidadẫos frente aos } \\
\text { efeitos da anarquia externa e } \\
\text { interna }\end{array}$ & \\
\hline $\begin{array}{l}\text { critério } \\
\text { moral }\end{array}$ & $\begin{array}{l}\text { respeito às normas acordas } \\
\text { no nivel supranacional }\end{array}$ & $\begin{array}{l}\text { Adequação do regime político às } \\
\text { expectativas dos cidadẫos }\end{array}$ & Eqüidade entre as partes \\
\hline
\end{tabular}

Chega-se assim, a um modelo simples de ordenamento político do meio internacional visto como legítimo que está resumido na figura 5. A validade teórica deste modelo deve ser encontrada no contraste com as teorias já aceitas por outros autores. Assim, observa-se que de fato o modelo assemelha-se muito com o desenvolvido por Buzan (1993), mas dele difere em uma dimensão qualitativa fundamental, na medida em que o modelo não entra no mérito da validade racional ou moral das normas criadas internacionalmente, esforço que pode levar à construção de modelos baseados em comprometimentos morais do próprio autor. Em última instância, as normas criadas pelo sistema político desenhado neste ensaio derivam sua própria legitimidade da legitimidade da estrutura e da legitimidade das partes componentes dessa estrutura, não entrando no mérito de que tipos de normas seriam aceitos pela coletividade. Procura-se, dessa maneira, desviar do debate tradicional na Escola Inglesa entre Pluralismo e Solidarismo, já que o modelo aqui apresentado aceitaria qualquer um dos estágios da sociedade internacional variando quais normas são aceitas pela Sociedade de Estados.

Finalmente, consolidado o arranjo político de governança, o próximo passo será submetê-lo ao teste da simulação histórica para avaliar como surge o fenômeno dos refugiados. Na próxima seção, na qual mostrarei como a variável tempo desempenha papel essencial na constituição do fenômeno dos refugiados, acuso que se deve prestar especial atenção para como reagem as exigências de legitimidade sobre as unidades e sobre o sistema político em primeiro lugar na formatação de uma nova categoria de indivíduos sem Estado e, em segundo lugar, na formatação de normas que visam restaurar o ordenamento do sistema. 


\section{A Interação Temporal: o Refúgio como Instituto da Sociedade Internacional}

Tendo identificado o sistema de organização política macroestrutural, passarei para o teste histórico no qual o sistema irá interagir com um mapa social complexo. Assumo, para tanto, uma relação com um mapa social dinâmico em que há diversas identidades coletivas configuradas, mas há também espaço para eterna reconstrução dessas identidades. Corroborando tal tese, já em meados do século passado Norbert Elias argumentava que as identidades coletivas se movimentam em constantes processos de incorporação, transformação, divisão, etc., de modo a constituir uma infinidade de possibilidades de entidades com poder de reunir convergência de identidade dos indivíduos. Para Elias, o Estado nacional, a família, a organização, a humanidade, todas são entidades que interagem e convivem no plano de possibilidades de identidade-nós (Elias, 2000).

A esse plano social, sobrepõe-se o sistema político desenhado na seção pregressa. Em um primeiro momento de interação teórica, permite-se, como definido anteriormente, total liberdade de ajustes para as massas que, buscando associar-se com aqueles com quem mais se identificam, passam a migrar de modo a formar diversas unidades homogêneas no seu nível de identidades coletivas nacionais. Ainda, impõe-se aos migrantes um véu de ignorância, semelhante ao proposto por Rawls (2002), cujo único objetivo é evitar que os indivíduos migrem por motivações diversas às de critério de convergência de valores no nível de identidades coletivas. Para tanto, os limites impostos por este véu de ignorância não são tão abrangentes quanto os formulados originalmente por Rawls. Impõe-se, somente, que os indivíduos desconheçam os fatores físico-geográficos e os recursos naturais e políticos das diversas localidades genéricas do globo. Além disso, os indivíduos também não têm conhecimento sobre seus próprios níveis de riqueza e inteligência para que não se reúnam de modo a concentrar parcelas distributivas em determinado território. Permite-se aos indivíduos apenas o conhecimento de seus próprios valores coletivos e culturais, de tal maneira garantindo que eles migrem apenas com o intuito de se organizarem em coletividades de acordo com critérios de convergência de identidade-coletiva.

Finalmente, em uma segunda etapa, submete-se o novo modelo conjunto (político e social) às designações de sua própria marcha 
histórica, portanto livre do véu de ignorância anterior, e espera-se que a organização em questão teria elementos para se reger em paz pela eternidade. No entanto, devido ao caráter dinâmico das formações de identidades coletivas da sociedade em questão é de se esperar que surjam novas minorias na seqüência do modelo e que essas minorias desejem - ou sejam forçadas a - se realocar no mapa político. Além do mais, nesse estágio se entendem os efeitos da retirada do véu de ignorância das diversas populações, que passam a migrar também em busca de recursos materiais que satisfariam suas necessidades de segurança e de bem-estar. Segue, em um estágio inicial dos desenvolvimentos da segunda etapa, que a sociedade de nações estaria insensível aos efeitos dessa migração e por isso permitiria o influxo de novas minorias para os seus territórios.

Nesse estágio, não há existência de refugiados, que são por definição indivíduos sem Estado, presos entre os desajustes gerados pela sobreposição da configuração política desenhada ao mapa social construído e transformado por uma dinâmica própria e complexa. Sua inexistência deriva do fato de que, nesse estágio, as sociedades estão, como em sua posição original, de portas abertas a esses novos fluxos de minorias. Esse estágio, definido no plano teórico, em muito se assemelha à configuração de Estados imperiais que se conformou com os tratados de Vestfália de 1948, quando o influxo de pessoas podia ser acomodado em sociedades que não haviam chegado aos limites da exploração de seus recursos; e também quando, do ponto de vista do monarca, mais nacionais significava apenas maior capacidade fiscal, meio imediato para aumentar o próprio poder nacional - única exigência de manutenção de segurança e de legitimidade interna. Assim, não podem os Huguenotes ser vistos como um fluxo de refugiados porque, como explica a própria Haddad (2003), estes foram incorporados na Inglaterra protestante, onde inclusive ajudaram na construção da identidade nacional.

Todavia, tendo as coletividades sedentárias enxergado que esses novos influxos de minorias em seus próprios territórios começam a reduzir a capacidade funcional de seus Estados protetores em dar-lhes as condições de segurança e bem-estar, começa um novo movimento de pressões para o fechamento de fronteiras e interrupção dos fluxos migratórios. Nesse sentido, condição necessária para a existência de refugiados é a decisão das unidades de se fecharem em si mesmas, por exigências de legitimidade funcional interna (definidas na seção anterior), e adotarem medidas de controle de fronteira, prática que se 
fortaleceu apenas com o desenvolvimento da sociedade vestfaliana para finais do século XIX.

No entanto, mesmo a imposição da citada condição não é suficiente para a configuração de refugiados. É necessário, para tanto, que as massas barradas em sua empreitada de penetrar territórios alheios sejam também impedidas de retornar à sua própria unidade de origem. Por isso, para que se configure a existência de refugiados é necessário imaginar que alguma condição impede o retorno no migrante ao seu próprio território. Além do mais, essa condição deve ser forte o suficiente para que os Estados aos quais os migrantes tentaram penetrar se sintam constrangidos, por força moral ou legal, a não os devolver a força pelo caminho de onde vieram. Se não pode um indivíduo retornar ao seu território de origem sob pena de ser sentenciado à morte ou à privação de seus meios de vida, provavelmente as outras unidades seriam constrangidas moralmente, quando não legalmente, a não rechaçar as minorias migrantes.

Finalmente, imaginadas as condições de criação de refugiados dentro na natureza do sistema desenhado, há ainda uma questão muito importante: o que é necessário para que o fenômeno dos refugiados se torne universal de modo que a própria estrutura política supranacional reivindique seu poder de deliberar sobre o tema?

Sobre esse aspecto, será necessário supor que, como se exige que o sistema político de governança seja funcionalmente benéfico, também se espera que, havendo uma anomalia implantada no próprio nível sistêmico e prejudicial para a Ordem internacional, o próprio sistema se encarregará de formatar normas que indiquem a conduta das unidades em ocasião de fluxos de refugiados. Não é possível garantir, todavia, que o instituto do refúgio e o princípio do non refoulement seriam eleitos pelas deliberações do sistema genérico aqui delineado. Características específicas do regime para os refugiados devem manter relações de causalidade com uma série de fatores conjunturais aqui não considerados. Alguém poderia pensar, por exemplo, em isolar todos os refugiados em um determinado território ainda não conquistado, criando para eles um novo Estado. Tal alternativa parece de fato ter sido considerada quando os europeus não sabiam o que fazer com os inflados fluxos de migrantes no contexto do entre-guerras (1919-1939). Não obstante, de acordo com as exigências de legitimidade inicialmente assumidas em relação à estrutura, espera-se que o sistema político encontre uma solução no nível macroestrutural para o problema e que essa solução não faça discriminação formal em relação às unidades 
soberanas. Sob tais restrições, espera-se que algo muito semelhante ao instituto do refúgio fosse formulado, desde que realmente houvesse uma necessidade de defesa da Ordem do sistema.

No modelo aqui desenvolvido, apenas duas situações poderiam implicar tais proporções: (i) uma drástica reconfiguração global do mapa social; e (ii) uma extensão forçada do modelo político para além de seus limites originais e rumo a um mapa social também complexo e dinâmico. Ambas essas situações hipotéticas parecem encontrar equivalentes na realidade quando, em um primeiro momento, muda-se, na sociedade internacional européia, a base de configuração social em espaços nacionais de um sistema de impérios multinacionais para um sistema de Estados nacionais (Haddad, 2003); e, em um segundo momento, estende-se mandatoriamente o modelo de configuração política desenhado historicamente para a sociedade européia rumo ao continente africano.

A primeira hipótese tem, portanto, força explicativa especial em relação à transformação social que impôs a primeira onda internacional de refugiados europeus, deslocados pela expulsão de minorias não mais bem-vindas na nova concepção de Estado nacional desenvolvida no entre-guerras. Na ocasião, fator indispensável para o entendimento da mudança é a conversão do princípio da autodeterminação dos povos para bases étnicas idealizado por Wilson que justificou novas transformações discursivas que enxergavam minorias étnicas como ameaça às integridades nacionais e consequentemente como injustificáveis pelas demandas de segurança das populações sobre as quais os Estados se propõem a exercer sua proteção.

Em um segundo momento, por outro lado, é a imposição do modelo político ao continente africano que gera uma nova onda de refugiados, para a qual o princípio de non-refoulement, base do regime de refugiados tal como desenhado na Europa parece ser visto com ressalvas na medida em que países europeus, agora sim enxergando o refugiado africano como ameaça externa, começam a propor que o refugiado migre para os países mais próximos entre outras abstrações egoístas baseadas na seletividade da porosidade lindeira imposta pela soberania das unidades políticas. 


\section{Conclusão}

No presente ensaio, mostrei como a imposição de um modelo de organização política pode gerar o fenômeno dos refugiados. Se em um primeiro momento o fenômeno parece inexistir, isso ocorre devido à imposição do véu de ignorância na posição original. No entanto, quando as diversas unidades passam a ser pressionadas pelas exigências de legitimidade interna, a solução natural é o fechamento de fronteiras rechaçando egoisticamente minorias migrantes. A condição essencial, todavia, para a criação do fenômeno dos refugiados é a existência de motivos de impedimento de retorno das populações migrantes aos seus territórios de origem. Essas imposições, só podem ser garantidas em um sistema que incorpore desenvolvimentos também num plano histórico.

É nesse sentido que a existência de refugiados não é uma conseqüência do sistema de Estados a não ser pela aceitação de que a mobilidade social do mapa das populações é uma característica desse modelo. Ainda, a variável temporal é essencial para o entendimento do fenômeno dos refugiados. Apesar disso, essa variável foi lembrada neste ensaio apenas como exercício de simulação teórica, o que se fez necessário para os fins a que se prestava o artigo. Em outra oportunidade, todavia, será necessário submeter o modelo teórico aqui apresentado ao contraste com os desenvolvimentos históricos.

Finalmente, vale sugerir um último exercício para preencher as lacunas deste ensaio: o de analisar como o jogo político interage com as exigências de legitimidade no nível supranacional para de fato estabelecer a normativa do instituto do refúgio. Neste artigo, assumiuse simplesmente que havendo a necessidade da proteção da ordem e da funcionalidade do sistema, o próprio sistema absorveria a responsabilidade pela institucionalização de normas para restituição da Ordem. Esse processo, todavia, é fruto de jogo político entre as unidades e não foi devidamente abordado neste artigo.

\section{Referências}

BOURDIEU, P. Razões Práticas: Sobre a teoria da ação. Campinas: Papirus, 1996.

BULL, Hedley. A Sociedade Anárquica. São Paulo: Editora

Universidade de Brasília, 2001. 
BUZAN, Barry. From International System to International Society: English School Theory and the Social Structure of Globalization. Cambridge: Cambridge University Press, 1993.

CAMPBELL, D. Violent Performances: Identity, Sovereignty, Responsibility. In: LAPID, Yosef; KRATOCHWIL, Friedrich. The Return of Culture and Identity in IR Theory. Londres: Lynne Rienner Publishers, 1996.

DICICCO, Jonathan; LEVY, Jack. The Power Transition Research Program: A Lakatosian Analysis. In: ELMAN, Colin; ELMAN, Mirium (Eds.). Progress in International Relations Theory: Appraising the Field. Cambridge, MA: MIT Press, 2003.

DUFFIELD, Mark. Global Governance and the New Wars: The Merging of Development and Security. London: Zed Books, 2001.

ELIAS, Norbert. The Civilizing Process: sociogenetic and psychogenetic investigations. Massachusetts: Blackwell, 2000.

FEARON, James; LAITIN, David. Ethnicity, Insurgency, and Civil War. American Political Science Review, v. 97, n. 1 p. 75-90, 2003.

FEARON, James. Separatist Wars, Partition, and World Order. Security Studies, v. 13, n. 4, p. 394-415, 2004.

FOUCAULT, Michel. Estruturalismo e Teoria da Linguagem. Rio de Janeiro: Editora Vozes, 1971.

FOUCAULT, Michel. Society Must Be Defended. London: Penguin Books, 2004.

GAT, Azar. War in Human Civilization. Oxford and New York: Oxford University Press, 2006.

GILPIN, Robert. War \& Change in Word Politics. Cambridge: Cambridge University Press, 1981.

GILPIN, Robert. Global Political Economy. Princeton: Princeton University Press, 2001. 
HADDAD, Emma. The Refugee: The Individual between Sovereigns. Global Society ${ }_{2}$ v. 17, v.3, p. 297-322, 2003.

JACKSON, Robert H. Governing Globalization: Power Authority and Global Governance. Cambridge: Policy Press, 2002.

KNORR, Klaus; ROSENAU, James (Eds). Contending approaches to international politics. Princeton, New Jersey: Princeton University Press, 1969.

KUHN, Thomas. Estrutura das revoluções científicas. São Paulo: Perspectiva, 1978.

MORGEnTHAU, Hans. A Política entre as Nações. São Paulo: Editora Universidade de Brasília, 2003.

POPPER, Karl; PETERSEN, Arne. The World of Parmenides. Great Britain: St. Edmundsbury Press, 1998.

RAWLS, John. The Law of the Peoples. Harvard: Harvard University Press, 2002.

SHAPIRO, Michael J. National Times and Other Times: Re-Thinking Citizenship. Cultural Studies, v. 14, n. 1, p. 79-98, 2000.

SCHMITT, Carl. The Concept of the Political. Chicago: Chicago University Press, 1996.

TICKNER, J. Ann, Re-visioning Security. In BOOTH, Ken; SMITH, Steve. International Relations Theory Today. Oxford: Polity Press, 1995.

WALTZ, Kenneth. Theory of International Politics. New York: McGraw-Hill, Inc, 1979.

WEBER, Cynthia. Performative States. Millennium: Journal of International Studies. v. 27, n. 1, p. 77-95, 1998.

WENDT, Alexander. Social Theory of International Politics. Cambridge: Cambridge University Press, 2007.

WIGHT, Martin. International Theory: the three traditions. Leicester: Leicester University Press, 1991. 